\title{
LA CONTRIBUCIÓN DE LOS ECLESIÁSTICOS NOVOHISPANOS A LA FORMACIÓN DE LA CONCIENCIA NACIONAL MEXICANA (SIGLOS XVII Y XVIII)
}

\author{
POR \\ Carmen José Alejos-Grau \\ Universidad de Navarra
}

\begin{abstract}
RESUMEN
En el presente trabajo se estudian más de cien sermones predicados en seis ciudades de México entre los años 1622 y 1777 . Su contenido demuestra la importancia que los predicadores tuvieron en la formación de una conciencia nacional mexicana ligada a la devoción a la Virgen de Guadalupe.
\end{abstract}

PALABRAS CLAVE: Sermones. México. Siglos XVII-XVIII. Virgen de Guadalupe.

\begin{abstract}
In the current article are studied more than hundred sermons preached in six cities of Mexico between 1622 and 1777. The article proves the importance that preachers had in the training of a Mexican national conscience bound to the devotion to the Virgin of Guadalupe.
\end{abstract}

KEY WORDS: Sermons. Mexico. XVII ${ }^{\text {th }}-X V I I^{\text {th }}$ centuries. Virgen de Guadalupe.

\section{ESTADO DE LA CUESTIÓN}

La oratoria sagrada mexicana es una fuente bien documentada, aunque poco estudiada, para conocer algunos aspectos de la historia de México. Uno de los temas más tratados, por esta oratoria, es la tilma de Juan Diego, en que quedó impresa la imagen de la Virgen de Guadalupe. Se puede decir, con verdad, que la devoción de los mexicanos a la Guadalupana es una manifestación constante en los sermones de los siglos XVII, XVIII y XIX. 
Un análisis detallado de los más de cien sermones guadalupanos que hemos estudiado, permite conocer el itinerario de esta devoción, parte de la religiosidad de los mexicanos y algunos hitos importantes de la vida del país. En efecto, en ellos se aprecian trazos de momentos importantes de la historia mexicana, como por ejemplo, la peste que asoló México en 1737, la confirmación del patrocinio de la Virgen de Guadalupe por Benedicto XIV, en 1754, las impugnaciones del milagro, etc. Los sermones se van haciendo eco de cómo fue arraigando en la piedad de los mexicanos esa devoción, de cómo se celebraron las diversas fiestas con motivo del patrocinio y de su confirmación, del impacto que producían las dudas sobre la Aparición milagrosa, etc.

En los sermones del siglo XVII, va unida la Virgen de Guadalupe con la defensa de ciertas prerrogativas marianas $y$, levemente, con ciertos rasgos mexicanos. Esta última tendencia nacionalista es habitual ya en los del XVIII y adquiere un tono creciente a medida que avanza el siglo. Como veremos, la formación de la conciencia nacional corre paralela, en estos sermones, a la similitud que descubren y subrayan los predicadores entre los elementos de la tilma, las características de la ciudad de México y la idiosincrasia de sus antiguos pobladores. Por ello se hace hincapié en una serie de términos que no es frecuente encontrar en otro tipo de documentos.

Los sermones que hemos seleccionado para nuestro estudio fueron predicados en diversas ciudades de Nueva España: Durango, Zacatecas, San Luis Potosí, Pátzcuaro, Querétaro y México, desde 1622 hasta 1777, y, casi todos en fechas notables: en el aniversario del día de la Aparición, la mayoría; con motivo de la construcción de un nuevo Santuario en 1709; para pedir que les librara de calamidades en 1711 y 1737; con motivo del Juramento del Patrocinio, en 1746, o de la confirmación del mismo, por Benedicto XIV 1755-1758, el 14 de diciembre ${ }^{1}$. Los lugares son variados: en la Catedral de México; en el Santuario de Guadalupe de México ${ }^{2}$ o de otras ciudades, en otras iglesias o en algún convento.

A partir de 1777 comienza lo que podríamos llamar la era de las impugnaciones $\mathrm{y}$, aunque los sermones guadalupanos conservaron ciertos rasgos nacio-

1 Alejando VII, en 6 de febrero de 1664, había concedido indulgencia plenaria a los que visitaran el Santuario de Guadalupe ese día. Vid. VelAZQUEZ, Primo Feliciano, La Aparición de Santa María de Guadalupe, Jus, México 1981, p. 277.

2 En las portadas de los sermones publicadosse señala el lugar donde se predican. A partir de los impresos en 1765 a Guadalupe se le nombra generalmente Colegiata y no Santuario (los que hemos consultado anteriormente a esas fechas no fueron predicados allí, por eso ponemos esa fecha como punto de referencia). En efecto, el Santuario de Guadalupe pasó a ser Colegiata por erección el 6 de marzo de 1749. Vid. VelAZQUEZ, Primo Feliciano, La Aparición de Santa María de Guadalupe, o.c., p. 261.

Actas del I Congreso de Historia de la Iglesia y el Mundo Hispánico Hispania Sacra 53 (2001) 
nalistas, se centraron, sobre todo, en la defensa del milagro ${ }^{3}$. Otra etapa interesante en la predicación en torno a la Virgen de Guadalupe son los primeros años del siglo XIX, en que se acude a su intercesión tanto desde el bando independentista como desde el españolista ${ }^{4}$. Sin embargo, puesto que nos propo-

3 A partir de 1777 empezamos a encontrar en los sermones una temática diferente. Es evidente que habían comenzado a aparecer con más fuerza dudas acerca del hecho milagroso que durante más de dos siglos nadie había impugnado. En septiembre de 1794 salió publicada la obra del español Juan Bautista Muñoz, en la que rechazaba el carácter milagroso de la Virgen de Guadalupe por carecer de documentos históricos escritos. El 12 de diciembre de ese mismo año, fray Servando Teresa de Mier predicó en la Colegiata de Guadalupe un sermón que le valió ser suspendido de predicar (Puede consultarse en la BNMx en R 232.931708 MIS.3. Ernesto de la Torre Villar lo publicó en Testimonios históricos guadalupanos, FCE, México 1984, pp........) Sin embargo, estos hechos venían precedidos por un cierto ambiente antiguadalupano, como muestran claramente algunos sermones (cfr. FERNANDEZ DE URIBE, José Patricio, Sermón de nuestra Señora de Guadalupe de México, predicado el 14.XII.1777. Impresa en México en 1801, R 880 LAF; del mismo autor es una obra publicada junto con el sermón: Disertación histórico-crítica en que el autor del sermón que precede sostiene la celestial imagen de María Santísima de Guadalupe de México, milagrosamente aparecida al humilde neófito Juan Diego. Escribíase por el año; LOPEZ MURTO, Antonio, María Santísima exaltada en la América por el cielo, la tierra y el infierno. Predicado en la Función de Acción de gracias, después del solemne Novenario con que el Ayuntamiento de San Luis Potosi celebra anualmente a su jurada Patrona María Santísima de Guadalupe, el 7 de mayo de 1791 en la Iglesia Parroquial. Impreso en México en 1791, R 1111 LAF; SAN CIRILO, Francisco de, Desempeños de la gratitud de María en su soberana imagen de Guadalupe. Predicado el 12 de diciembre de 1795. Impreso en México en 1796, R 1111 LAF; PEREZ DE ANASTARIS, Ramón, Sermón, que en el día de la milagrosa aparición de Nra. Sra de Guadalupe dijo en su Santuario en el mes de diciembre de 1796. Impreso en México en 1797, R 1328 LAF. Durante los primeros años del siglo XIX los sermones guadalupanos van a repetir ideas y se van a centrar, fundamentalmente, en la defensa de la tradición: HEREDIA Y SARMIENTO, José, Sermón panegírico de la gloriosa aparición de Nuestra Señora de Guadalupe. Predicado el 12 de diciembre de 1801. Impreso en México en 1803, R 436 LAF; URAGA, Antonio María, Discurso panegírico de María Santísima de Guadalupe. Predicado en Valladolid (México) el 12 de noviembre de 1808, R 438 LAF. Todos los sermones que citaremos se encuentran en la Colección Lafragua de la Biblioteca Nacional de México, Fondo Reservado. A partir de ahora daremos sólo la signatura del volumen donde se encuentra el sermón.

4 LEZAMA, José de, Exhortación de paz que, descubierta la infame revolución tierra adentro, predicó...en fiesta de María Santísima de Guadalupe. Predicado el 12 de enero de 1811 . Impreso en México en 1811, R 1277 LAF; BRINGAS, Diego Miguel, Sermón, que en la solemne función que en acción de gracias por la insigne victoria conseguida contra los insurgentes en la toma del inexpugnable fuerte de Tenango del Valle, el sábado 6 de junio de 1812 celebró en honor de María Santísima de Guadalupe, la División mandada por el señor don Joaquín del Castillo y Bustamante. Predicado el 13 de junio de 1812. Impreso en México en 1812, R 1342 LAF; GARCIA DE TORRES, José Julio, Sermón de acción de gracias a María Santísima de Guadalupe por el venturoso suceso de la Independencia de la América Septentriona. Predicado el 12 de octubre de 1821. Impreso en 1821, R 1821 M4GAR; BARREDA Y BELTRAN, José María, Sermón que en celebridad de la maravillosa aparición de nuestra señora la Santísima Virgen María de Guadalupe. Predicado el 12 de diciembre de 1822 en Puebla de los Angeles. Impreso en Puebla en 1822, R 1278 LAF; BURGOS, Manuel de, Sermón panegírico de María Santísima de Guadalupe que en la solemne función de los Patriotas de Querétaro le hicieron en acción de gracias por los triunfos continuos que ha concedido a la Patria. Predicado el 6 de enero de 1829. Impreso en Querétaro, R 208 MIS.2.

Actas del I Congreso de Historia de la Iglesia y el Mundo Hispánico Hispania Sacra 53 (2001) 
nemos conocer cómo contribuyeron los eclesiásticos a la formación de la conciencia nacional, nos centraremos exclusivamente en las fechas ya indicadas: 1622-1777.

\section{EL NACIONALISMO EN LOS SERMONES DEL SIGLO XVII}

El primer sermón ${ }^{5}$ que reivindica la figura de Guadalupe, en que ya aparece como algo propio y exclusivo de los mexicanos, es el de José Vidal de Figueroa $^{6}$, predicado en 1661. Entre varias ideas de mucho interés, apunta cómo la Virgen de Guadalupe constituye una «predestinación singular» para México (f. $12 r$ ), ya que, como comenzaban a flaquear las fuerzas de algunos ministros evangélicos para la conversión de los indios, «quiso Dios asegurarlos con este milagro»; y la señal más evidente fue utilizar la manta de los indios, que «siendo tan basta, y tan tosca que es de maguey, planta propia desta tierra, como la tilma es propio traje de sus Indios solos» (f. 10v).

El franciscano Juan de Mendoza predicó en 1672 un sermón en el convento de San Francisco en México ${ }^{7}$. Sus reflexiones acerca de la concordancia que hay entre la Imagen de Guadalupe y «el original del Cielo» (p. 8) admite el hecho milagroso de que, a partir de unas flores, surgiera «esta Imagen Santa [...], porque creemos, que la mano de Dios se ocupó, y se empleó en su fábrica: y porque su fábrica misma está diciendo es obra de la mano de Dios» (p. 16). El fin de esta aparición es hacer de Nueva España un Cielo (cfr. p. 21). Pero, ¿cuál es el atractivo que tiene esta Imagen para el mexica?, y contesta:

«Formóse esta Imagen Santa de Guadalupe, a semejanza de los Gentiles naturales de esta tierra, dícelo su rostro, que muestra un color apagado, y moreno, semejante al que tienen ellos: y púsose asímismo en su traje, vistióse las ropas a su usanza, para que viéndola los Gentiles formada a su semejanza, y vestida en su traje, se le enamorasen, y convirtiesen. Así sucedió: pues luego detestaron sus Idolatrías, recibieron el Evangelio, y empezaron a mirar con cariño la fe de Cristo, que antes miraban con ceño» (p. 23)

\footnotetext{
5 Hay otro anterior, de 1622, predicado por Juan de Cepeda guardado en la BNMx con la signatura R 1622 M4ZEP, en el que no aparece ningún rasgo nacionalista: Sermón de la Natividad de la Virgen María Señora nuestra, predicado en la ermita de Guadalupe, Extramuros de la Ciudad de México en la fiesta de la misma Iglesia.

6 VIDAL DE FIGUEROA José, Theorica de la prodigiosa imagen de la Virgen Santa María de Guadalupe en México. Predicado el día 12 de diciembre de 1660 en la ermita de Guadalupe. Impreso en México en 1661, R 1622 M4ZEP.

7 MENDOZA, Juan de, Sermón en el día de la Aparición de la Imagen Santa de Guadalupe. Predicado el 12 de diciembre de 1672 en el convento de N. Padre S. Francisco de México. Impreso en 1673, R 1622 M4ZEP.
}

Actas del I Congreso de Historia de la Iglesia y el Mundo Hispánico Hispania Sacra 53 (2001) 
Nueve años más tarde, el 12 de diciembre de 1681 en Querétaro, Juan de Robles resaltaba el hecho de que a pesar de las humedades de México, «que consumen en menos tiempo materias más sólidas, más resistivas y permanentes» (f. 4v), seguía intacta el ayate de la Imagen. De ahí deduce que, en la línea del milagro, no se ha hecho otro más grande y ha sido el mayor beneficio a México y, por tanto, es una muestra de que los novohispanos son preferidos por la Virgen «a todos los del mundo» (f. 7v), y que de hecho «vino del Cielo para vivir y estar entre nosotros» (f. 8r).

\section{LOS SERMONES DEL XVIII}

Algunos de los aspectos que ya habían aparecido en el siglo anterior, se repiten insistentemente y con más fuerza en el XVIII: la consideración de la Aparición de la Imagen como un milagro; que la Virgen se apareció para destruir la idolatría, en concreto el ídolo Teotenantzin que se adoraba en el cerro del Tepeyac; el asombro que produce la incorruptibilidad de la Imagen a pesar de estar pintada sobre un ayate de tela burda, hecha con los hilos del maguey, y de los aires húmedos de la Laguna mexicana; que María de Guadalupe es madre especial de los indios; y, finalmente, la conciencia de que la Virgen de Guadalupe es algo especial para los mexicanos, no comparable con cualquier otra advocacion mariana. Esto último es lo que impulsará una creatividad increíble a la hora de la predicación para hacer comparaciones, símiles entre textos de la Sagrada Escritura o de los Padres o teólogos con los elementos que aparecen en la pintura Guadalupana y con los rasgos más netamente nacionales.

\subsection{Primeros años del siglo XVIII}

En los primeros once años de siglo XVIII encontramos varios sermones interesantes en que se anuncian elementos que desarrollarán con constancia y desde distintos puntos de vista los predicadores posteriores. Como en el siglo XVII también aquí se une la Virgen de Guadalupe a la Inmaculada Concepción, como se aprecia en un sermón de 1700 en que se une esta prerrogativa al de «el divinizado Phenis que florece en la palma de una tilma: ésta es el Ave singularmente famosa por exempta del general resbalón: ésta el Pájaro nacional de nuestras Indias» ${ }^{8}$.

8 LoBAto, Juan Antonio, El Phénix de las Indias único por Inmaculado floreciendo en una tilma de Palma María en su concepción purísima aparecida en Guadalupe trasuntada en Thamar y 
Desde la inicial ermita de Guadalupe hubo una serie de construcciones encaminadas a albergar el creciente número de fieles devotos de la Virgen de Guadalupe. El 27 de abril de 1709 se bendijo uno nuevo que fue dedicado con extraordinaria pompa ${ }^{9}$. El día octavo del Novenario a la Dedicación del nuevo Templo, Juan Goicoechea predicó un sermón de enorme interés ${ }^{10}$ en lo más interesante es la comparación de la Guadalupana con los símbolos más netos de los mexicanos:

«Vos sois aquella Augural Aguila, Blasón Augusto de la Cristiana México; como lo fue de su Fundación Gentil la Peña, el Tuno y el Aguila. Aguila a quien se fabrica, en el monte Tepeya, este encumbrado Nido. Vos sois la Luna llena, que le dio a la Corte Católica de esta Septentrional America, el nombre de Meztli o México; que como Jericó se interpreta Luna; y se os dedica, como en casa de Zaqueo, templo al Sol; a vos Rosa de Jericó Luna del Mar Mexicano, un nuevo Cielo.» (pp. 4-5).

La Imagen es un Milagro que pertenece sólo a los mexicanos y compara su permanencia intacta a pesar de los años y los aires húmedos de la Laguna, con la Eucaristía en la que Cristo está sacramentado como la Virgen de Guadalupe que se «quedó como sacramentada en una Capa» (p. 27).

Ese mismo año en Zacatecas, José Guerra, el día de la Aparición ${ }^{11}$, en un sermón hacía referencia a algunos de los rasgos que acabamos de señalar: el favor especial de la Virgen a México y su aparición en un ropaje humilde; sin embargo aporta algunos datos nuevos de interés. El constitutivo de María es ser Madre, pero nunca se ha manifestado con más claridad Madre, que cuando se apareció en su milagrosa Imagen de Guadalupe (cfr. f. 4r); María desea quedarse con los mexicanos en su Imagen hasta el fin del mundo (cfr. f. 5r) y deseó que se construyera su templo en un lugar de paso para que todos puedan acudir con facilidad como hijos; María se viste con la ropa de los indios para rogar especialmente por ellos; intercede en la tarea misionera de todo el territorio de Nueva España: «Cuántos Idolos ha destruido la Gran Señora por me-

aplaudida de Judas Pharés, y Zarán con emblemas, empresas o heroglíficos. Impreso en México en 1700, R 1622 M4 ZEP y R 1148 LAF. 273.

9 Vid. VELAZQUEZ, Primo Feliciano, La Aparición de Santa María de Guadalupe, o.c., pp. 251-

10 GoICOECHEA, Juan de, La maravilla immarcesible y el milagro continuado de María Santísima Señora nuestra en su Prodigiosa Imagen de Guadalupe de México. Compite firmezas con su nuevo Templo, que la copia: adelanta duraciones al Cielo, que a su Efigie traslada: iguala permanencias el Augusto Sacramento, de quien imita la Milagrosa Presencia en su Pintura. Impreso en México en 1709, R 612 LAF. Juan de Goicoechea nació en San Luis Potosí en 1670, entró al noviciado de los jesuitas en 1685 e hizo sus votos solemnes en 1704. Murió en 1734.

11 GUERRA, José, Sermón de nuestra Señora de Guadalupe, que en el día de su Aparición en su Colegio de Misioneros de la Ciudad de Zacatecas predicó. Impreso en México en 1709, R 1701 M4 JUA.

Actas del I Congreso de Historia de la Iglesia y el Mundo Hispánico

Hispania Sacra 53 (2001) 
dio de sus Soldados Evangélicos! Díganlo las partes por donde hemos hecho Misiones. Y cuántos espero yo destruirá en esa infernal Sierra de Nayari, mediante sus misioneros» (f. 7r). Finalmente llama a Guadalupe: «la honra de nuestro Americano Pueblo; pues lo has honrado con tu Milagrosa Aparición» (f. 9r).

En 1711 con motivo de unos temblores de tierra y enfermedades que asolaban México se acudió a la Virgen de Guadalupe para que hiciera cesar esas calamidades. El predicador en el sermón ${ }^{12}$ del 20 de diciembre parece dar a entender que para los mexicanos la Imagen de Guadalupe es la Imagen de la Virgen, como si estuviera en persona:

«Pues comienzo y digo: que pido a María nos comunique las gracias de que no tiemble la tierra, de que no haya más incendios, ni la enfermedad prosiga. No lo he dicho bien. Pues pedir esto a María es pedirlo a su persona, y a mi me mandaron que lo pidiera a su Imagen. Pues emmiéndome, y digo: que pido a la Imagen de María nos conceda las tres gracias, y pido bien pues si la persona de María nos las puede conceder, su Imagen podrá otorgarlas» (f. 3 r).

Y para que nadie se llame a engaño y piense que suceden esas calamidades porque no existe la especial protección de María dice que la culpa es de la maldad de los hombres y de no hacer acudido antes a la Virgen de Guadalupe para pedirle que les proteja.

\subsection{Sermones sobre el Patrocinio de la Virgen de Guadalupe}

\subsubsection{Bartolomé de Ita y Parra, predicador guadalupano}

Entre 1731 y 1746 Bartolomé de Ita y Parra ${ }^{13}$ predicó unos sermones de enorme interés, en primer lugar porque, por tener fama de buen orador, los predicó en momentos importantes de la historia guadalupana, y en segundo lugar porque su contenido es muestra del fervor creciente del pueblo mexicano en torno a la Virgen del Tepeyac.

12 AYALA, Antonio de, Deprecación que por los temblores de tierra, fuego y enfermedades, a la Sagrada Imagen de Nra. Señora la Virgen María con el título de Guadalupe. Impreso en México en 1712, R 1701 M4 JUA.

13 Bartolomé Ita y Parra nació en la ciudad de México en el último tercio del siglo XVII. Hijo de familia noble se graduó como maestro de Artes y se doctoró en Teología en la Universidad de México. Fue un importante orador sagrado y publicó muchos de sus sermones entre los años 1712 y 1747.

Actas del I Congreso de Historia de la Iglesia y el Mundo Hispánico Hispania Sacra 53 (2001) 
El de 1731 lo predicó ${ }^{14}$ el 12 de diciembre en el Santuario de Guadalupe con motivo del segundo centenario de su Aparición. Estaban presentes el Virrey, Marqués de Casa-Fuerte, la Real Audiencia, el Eclesiástico Cabildo, con el Prelado (será el arzobispo?, en ese momento era Juan Antonio de Vizarrón, y Eguiarreta) y los demás Tribunales.

El punto alrededor del que gira todo el sermón es presentar la Virgen de Guadalupe como Señora de los Tiempos. Comienza diciendo:

\begin{abstract}
«Y tenemos en el Evangelio los Siglos, adorando a María por su Reyna; veamos como veneran a esa Imagen por su Señora. Se formó milagrosamente en la Oficina de la Omnipotencia, fue su Pintor el Angel Custodio de este vastísimo Imperio de las Indias; que en lugar del fecit, se retrató a los pies de su Emperatriz, ofreciéndole para que lo ampare a su recomendado Reyno, en la Luna de su Capital, que eso significa México.

Es cierto Señores, que en estas obras, que son Milagros de Dios, como executadas de Artífice tan Sabio, no se reconoce en ellas cosa alguna, que no sea un Mysterio. (...) pues como puede creerse, que en esa Celeste Copia, cada rasgo no sombree un prodigio? (pp. 5-6)
\end{abstract}

Y a partir de aquí describe todos los elementos que aparecen en la pintura como expresión de un prodigio. En primer lugar, enumera los cuerpos celestiales que aparecen en la Imagen: 46 estrellas, la luna a los pies, un sol con 100 rayos. ¿qué significan estos elementos? Los cien rayos expresan que los siglos tributan a la Virgen y los doce que le forman la corona «que la señora como Reyna de los Años, se corona con sus doze meses» (p. 7). Tanto la situación del Sol, que le forma el Trono, como de la Luna que la tiene como de repisa son símbolo y anuncio de permanencia de la Imagen.

Señala que fue una aparición pública porque no fue entre las sombras de la noche, sino entre las luces de la Aurora; no en una Casa privada, sino en un Campo; y fuera de la Ciudad, porque se apareció a Juan Diego en una Montaña. La Virgen de Guadalupe se inclinó «a los humildes Valles de nuestra despreciada tierra (...) nos mira amorosa, y nos atiende afable» (p. 10). Por tanto todas las luces que aparecen en el lienzo «es decirnos en elegante símbolo, que esa bella Imagen recopila en sí todos los Tiempos, junta todos los Años, contiene todos los Siglos» (p. 12). Y una muestra más de que la Virgen de Guadalupe contiene todos los siglos es su permanencia en un ayate hecho con mate-

14 ITA Y PARRA, Bartolomé Felipe de, La imagen de Guadalupe, Señora de los tiempos. Impreso en México en 1732, R 1338 LAF. Con motivo del segundo centenario Miguel de Aroche predicó otro sermón en que resalta la permanencia de la pintura debido a que María quiso poner en México esa Imagen para que sólo la gocen los «moradores dichosos de nuestra América» (p. 4), Flor de la edad de la milagrosa imagen de María Santísima en su concepción en gracia. Impreso en México en 1732, R 1701 M4JUA y R 1114 LAF.

Actas del I Congreso de Historia de la Iglesia y el Mundo Hispánico Hispania Sacra 53 (2001) 
ria corruptible, en un clima salitroso «sin resolverse sus hitos, sin despedirse sus colores, sin apagarse su viveza, sin borrarse su Imagen, sin marchitarse su hermosura. Columna permanente que dura y durará formada de Dios, como la otra sobre la levedad de la Nube, in columna nubis, en la frágil materia de esa Manta, para guiar al Cielo al Indiano, como allá a la tierra de Promisión al Israelita» (p. 13). $\mathrm{Y}$ eso le lleva a exclamar: « $\mathrm{O}$, y como si tuviésemos tiempo, desafiara Yo en nombre de nuestras Indias, a las Naciones del mundo, para vencerlas a todas juntas, solo con ese pobre Ayate!» (p. 12).

Esa prueba del cariño de la Virgen por dejar su retrato en la Imagen es devuelto por los mexicanos aunque «nuestro agradecimiento, nunca acertará a explicarse nuestro cariño, reconocido siempre de lo que le debe a tu amparo» (p. 15). Amparo que es patrocinio perpetuo ya que «esta tu Soberana Imagen pensó elevada pluma, es Retrato perfecto tuyo, como decretada en la eternidad, y de esta anterior existencia tuya. Ab initio et ante saecula creat sum (Eccle. 24), es ilación legítima tu futura duración, hasta el último siglo, et usque ad futurum saeculum non desinam» (pp. 15-16).

A continuación busca un nuevo apoyo para defender la permanencia eterna de la Imagen de Guadalupe. Para ello acude a la Eucaristía. Tomando como referencia a Santo Tomás de Aquino explica que «durará la Eucaristía en la Iglesia, en la noche de este siglo, y entre las sombras oscuras de la fe, desapareciéronse al rayar el día de la eternidad, en las luzes de la Gloria» (p. 18). Pero la Virgen de Guadalupe se apareció «al tiempo, que se dudaba, si eran racionales los Indios por aquel su infame delito, de comerse unos a otros, lo que no se dice de las fieras: $Y$ tomando la Señora su Manta, para coparse en ella, declaró con la acción, que se continuase su Conquista, porque eran capaces como las demás gentes de transformarse en Dios por su gracia, y por su vista» (p. 19). Es decir, se apareció al rayar el Alba y, por tanto, se «puede sospechar la devoción, que no acabará en la negra noche de esta vida, sino que se trasladará a la Gloria, para durar eterna» (p. 19). Concluye el sermón recordando a los mexicanos que para seguir manteniendo el favor de la Virgen es necesario que corrijan sus culpas.

La peste de 1737 movió a los mexicanos a jurar el Patronato de Nuestra Señora de Guadalupe. El Ayuntamiento de México, recordando que con motivo de las inundaciones de 1629 , se trasladó la Imagen de Guadalupe a la ciudad de México, pidieron la Arzobispo José Antonio Vizarrón y Eguiarreta lo mismo. Este prefirió que el Ayuntamiento promoviera algún acto de piedad pidiendo la intercesión de María de Guadalupe. Se hizo el novenario al cual pertenece el sermón de Ita y Parra predicado el 7 de febrero. Como no decrecía la epidemia se decidió el 11 de febrero del mismo año jurar como Patrona de la 
ciudad de México, su distrito y jurisdicción, a la Virgen de Guadalupe ${ }^{15}$, acto que se hizo el 27 de abril en la real capilla del palacio donde vivía el arzobispo virrey. Se dio noticia del Juramento a todas las ciudades, villas o pueblos, hasta los más pequeños lugares, y se invitó a nombrar sus delegados o remitir poderes para la Jura Nacional. Por diversos motivos no pudo hacerse esta Jura hasta 1746. Se acordó que el juramento fuera prestado en manos del arzobispo el 10 de diciembre, que el 11 hubiera una procesión solemnísima y el 12 en el santuario de Guadalupe, durante la Misa, se leyera el edicto en que el prelado anunciase el Patronato principal de la Virgen de Guadalupe sobre toda la nación. Aunque en realidad el juramento se hizo el 4 de diciembre por la mala salud del arzobispo, el día de la Aparición se hizo con toda solemnidad en el santuario; después de la Jura, Bartolomé Ita y Parra predicó el sermón ${ }^{16}$ pidiendo la salud de los mexicanos, de ahí el título con que lo publicó. En este sermón vuelve a hacer hincapié en la especial predilección de la Guadalupana por los indios.

Por el contenido del sermón parece que se hizo un novenario a la Virgen de los Remedios, pero como no se terminaba la epidemia se decide hacer otro novenario a la Virgen de Guadalupe «pero con esta notable diferencia, y es la primera duda: A la imagen de los Remedios la trae la Ciudad a su Iglesia para pedirla: a la imagen de Guadalupe viene la ciudad a su Iglesia para rogarla. Pues ¿por qué la Imagen de los Remedios viene a la Ciudad, y la Ciudad viene la Imagen de Guadalupe?».

Hace una sencilla comparación entre una y otra advocación para demostrar que la propia mexicana es la de Guadalupe y por eso es lógico que se acuda a ella porque es la que les protege de modo particular. La Virgen de los Remedios fue traída de Europa, y no tiene casa propia, toda América es su Templo; en cambio, la de Guadalupe «nació aquí: aquí se apareció en este lugar: a este territorio eligió para Palacio de su soberanía, para Casa de su majestad, para Trono de su grandeza. Y decidme, señores, no piden las leyes de la cortesía, y del respeto, que caminen sus vasallos, y los súbditos a los Palacios de sus Soberanos, para suplicarlos los favores de su gracia? Pues camine la Imagen de los Remedios a México, para que allí se le pida, que a su Casa va; y venga México a Guadalupe, que a su Palacio viene, para suplicarla su patrocinio.

15 Vid. VelazQueZ, Primo Feliciano, La Aparición de Santa María de Guadalupe, o.c., pp. 279283. Cayetano Cabrera, describió con todo detalle este suceso en su conocida obra, Escudo de armas de México. Año de 1746. R 1746 M4CAB. Los oradores Capitulares que predicaron en esas festividades en el Santuario los primeros años fueron: D. José de Elizalde Ita y Parra (1737), D. Juan Antonio de Fábrega Rubio (1738), D. Manuel de Urruzaustegui (1739) y D. Bartolomé de Ita y Parra (1740).

16 ITA Y PARRA, Bartolomé Felipe de, La Madre de la Salud, la Milagrosa Imagen de Guadalupe. Impreso en Madrid en 1739, R 1338 LAF.

Actas del I Congreso de Historia de la Iglesia y el Mundo Hispánico Hispania Sacra 53 (2001) 
Esta razón, al probarla con la Escritura, le dará campo a la alabanza ceñida a nuestra congoja» (p. 4).

También compara la Virgen de los Remedios con el Arca que los israelitas llevaban allí donde iban. Pero la de Guadalupe es como la Zarza de Moisés que estaba firme en un lugar y allí es donde le dictó Dios a Moisés las lecciones con que libertaría a su Pueblo de la apretada esclavitud que padecía, y donde debía ir a venerar a su Dios el pueblo de Israel. Y deduce: «Hasta esta tierra de Guadalupe, en que se apareció la Zarza de esa Imagen de María, es santa; por eso hemos de venir aquí a adorarla» (p. 10).

A partir de este momento explica porqué se acude a la de Guadalupe, aunque, en realidad, no hay incompatibilidad entre una advocación y otra porque «es la Imagen de los Remedios la que nos trae a la Imagen de Guadalupe, para que nos sane de la epidemia. En lo secreto nos sana (creedlo) la Imagen de los Remedios; pero en lo público, nos da la salud la Imagen de Guadalupe»(p. 14). Esto es así porque los enfermos a quienes se ha de hacer el milagro son los Indios, que son hijos especiales de la de Guadalupe, y tocan a su particular amorosa jurisdicción; si la Virgen de Guadalupe hace patente su santidad, favorecerá que disminuya «la tibieza de su fe, crezca en ellos para con la Santa Imagen, su culto, y veneración»(p. 16). Para demostrar esta especial predilección por los indios señala que en los pueblos de alrededor hay enfermos por la epidemia, pero no hay ningún enfermo entre los habitantes de Guadalupe. Y recuerda que «el año de mil quinientos y quarenta y quatro se encendió en los Indios una terrible peste, que dentro de pocos días quitó la vida a más de doce mil de ellos: vinieron desde Santiago en procesión a pedirla su remedio esta Santa Imagen, y al punto cesó el contagio» (p. 13).

Esta especial protección de los Indios la desarrollará más ampliamente en los sermones que predicó en 1743 en la fiesta de la Aparición en el Santuario de Guadalupe y en el ya citado de 1746.

En el de $1743^{17}$ acude a la comparación entre la imagen de la Virgen impresa en el Ayate con la Encarnación del Verbo y con la Eucaristía. Comienza diciendo que la Virgen quita el Ayate a Juan Diego y deja impresa su imagen. Al quitarle la capa le quita a los indios su vestido, su cama, porque es lo único que tienen para vestir y para descansar.

«Dios me dé luz para explicarme, y sea la de S Ambrosio lo que me alumbre: parece, que corta su pluma a mi intento: Ad imaginem haec Imago venit ad terras (S. Ambroșio In Psalm 38). Encarnando el Verbo, la Imagen vino a la tierra, y vino a otra Imagen. Está profundo quiere decir que como el Verbo era Imagen sustancial del Padre y el Hombre fue

17 ITA Y PARRA, Bartolomé Felipe de, La imagen de Guadalupe, imagen del Patrocinio. Impreso en México en 1744, R 1338 LAF.

Actas del I Congreso de Historia de la Iglesia y el Mundo Hispánico Hispania Sacra 53 (2001) 
criado a Imagen de Dios: encarnar, fue venirle a la tierra una Imagen. Hoy con nuevo sentido se lee al Santo: la Imagen que vino a la tierra encarnando al Verbo, se apareció para original de esta otra Imagen, que formó María, dejándose ver en Guadalupe» (pp. 3-4)

El fin de esta aparición la señala a continuación:

«O dignación del amor de María a estas Naciones Gentiles, inclinadas a la idolatría (...) Esta Imagen de Cristo que se imprimió en la capa de la humana naturaleza, se apareció para favorecerla» (pp. 5-7)

\section{Pero matiza:}

«Yo no digo que encarnó María apareciéndose en Guadalupe, pero ignoro que se dé cosa mas parecida a la Imagen del Verbo Encarnado que esta de María en Guadalupe, apareciéndose» (p. 8)

A continuación explica cómo es esta similitud. Del mismo modo que en la Encarnación no se puede separar la naturaleza humana de la divina porque dejaría de ser Dios o de ser Hombre, así está unida la imagen de la Virgen al Ayate «deshaced el Ayate, se perdió la Imagen. Dura esta, permanece aquel» (p. 8). En lo material lo que tomó María fue la capa pero en lo formal «lo que unió a sí fue a nosotros, y a nuestro espíritu» (p. 9).

María para favorecer a los Indianos les quita la capa y esto es lo que asegura «todos días un indefectible Patrocinio» (p. 12). Para explicar esto acude a un texto del Exodo $(22,26)$ en que manda Dios que si al favorecer a uno, en prenda del favor, que se le hace, se toma o recibe del favorecido la capa o vestido, hay que devolvérselo antes que se ponga el Sol. Y añade:

«Las razones (vean pintados a nuestros Indios) porque ese pobre no tiene otra cosa con que cubrirse (...) eso es todo su vestido (...) esa es toda su cama: eso es todo su descanso: no tiene otra cosa en que dormir [...] Todo esto le quita María Santísima estampando en la capa su imagen por favorecerle. Conque se queda el pobre desnudo, sin su vestido, sin su abrigo, sin su descanso, sin su lecho. En estos términos habla la Ley de la capa de este pobre, y en fuerza de su cumplimiento antes que el sol se ponga todos los días debe la Señora volvérsela (Ex 22,26). Este es el caso, la obligación insta de volver al Indio la capa, pero como ya en ella está estampada María, no puede restituírsela sin darle la Majestad a sí misma: y ven aquí, que porque María Santísima favoreció a los Indianos quitándoles la capa todos los días al volvérsela en fuerza de la Ley los asiste perpetuamente sin dejar jamás de ampararlos» (pp. 12-13).

A continuación compara la Virgen de Guadalupe con la Eucaristía: del mismo modo que la Virgen protege todos los días a los Indios, lo mismo hace 
el Señor en la Eucaristía. Para explicarlo acude al Aquinate (Quod de nostro assumpsit totum nobis contulit ad salutem (TAQ, opsc 57)) que señala que el Señor asume nuestra naturaleza y la mejora; además también es doctrina católica que al comulgar el cristiano se hace una cosa con Cristo. Esto lo aplica a la Guadalupana en este fragmento tan singular:

\footnotetext{
«Así vuelve Dios la capa que toma, y así vuelve María la capa en que se estampa, haciendo a los que favorece tan unos consigo, que puede decir el Indiano, que por esta circunstancia es especialísimo hijo de María Santísima de Guadalupe. Esta es una filiación tan nueva, que juzgo no se ha oído, ni se ha pensado hasta ahora. Todos son hijos, porque sus Madres los conciben y los paren. Los indios o Indianos son unos Hijos de María, que la Señora los concibe, pero nunca los pare. Oídme. La Madre cuando concibe, tiene al hijo consigo, lo mantiene dentro, se está junto con él: cuando le pare le separa de sí, le aparta, ya no sólo son distintos sino también separados. Ahora, pues, díganme. Los Indios o Indianos ¿son hijos nacidos de esa Imagen, o solo son concebidos? Nacidos; no; porque no pueden separarse de ella; si se separa la capa (que son ellos) no habrá tal Imagen: luego no nacen; si no nacen, no los pare María; concíbelos sí, pero sin parirlos nunca, pues siempre se están dentro, siempre a su Majestad unidos, siempre sin separarase uno de otro. Todos los fieles son Hijos de María pero como nacidos, separados; los Indianos como no paridos, sino concebidos, nunca se ven apartados. Diré: que son unos hijos, que siéndolo, y no naciendo, se están siempre engendrando. Diré, que todos los demás fieles son Hijos de María ad extra, como paridos, solo los Indianos por no nacidos son unos Hijos ad intra» (pp. 15-16).
}

Los Indianos obtienen en esta Soberana Imagen la especial prerrogativa de una adopción de identidad, que excluye toda separación: y en ella está basada «la rarísima felicidad, que concibiéndolos y no pariéndolos, siempre los tiene consigo» (p. 17). Y además es el fundamento de la felicidad futura en la Gloria, porque «si nacemos es en el Cielo, es en la Gloria, para donde nos lleva su Patrocinio a presentarnos, como Hijos suyos, a Dios y a su Trono» (p. 21).

Destaca que este favor sólo lo ha concedido María a los Indianos, que son los que tienen mayor honra y gloria porque al elevarles a formar con su espíritu su Imagen en la de Guadalupe, les coloca en una categoría superior a las demás Naciones, porque es la gente más unida a ella. Sin embargo, ¿qué tienen éstos a pesar de que los europeos les califican de salvajes (Moreri), brutales (Duveton), incapaces de alcanzar la salvación, etc.? Y como contestación a los calificativos negativos destaca cómo la Virgen supo adaptarse a ellos que aunque no conocían la escritura sí sabían interpretar las pinturas y por ello se imprimió en un lienzo. ¿Y qué enseña esa pintura?:

« $\mathrm{i}$ paysanos míos, como quisiera declararos lo que esa maravillosa pintura os enseña! No se forma su imagen de las espinas del pecado, resulta de las flores de la virtud: no se eleva al Hombre a tan celestial Copia mientras vive asido a los bienes caducos, entonces se 
sublima, cuando misericordioso, y devoto se desnuda para dárselo todo a Dios, a él se viene el Cielo en las Estrellas, en el Sol, y Luna, cuando deja lo que es todo tierra» (p. 30).

Y para terminar insiste en la intercesión de María:

«Señora, María Santísima, ya te nos acercaste apareciéndote: propinquus es: en esa capa en que te estampaste está figurado tu Patrocinio: extiéndelo sobre todos tus esclavos, que son los Fieles (...): abríguelos tu poder, cúbralos tu amor, defienda tu capa a los que a tu sombra asegurados esperan conseguir la gracia, y alcanzar la gloria» (pp. 30-31).

El sermón predicado por Ita y Parra con motivo de la Jura Nacional en $1746^{18}$ tiene un título que expresa la mutua relación establecida entre Guadalupe y los Indianos y el contenido responde a ello. Hace una comparación entre la Nación mexicana y la manta en la que se imprime la Virgen:

«Imprime en la manta del Indiano su Imagen. Esto fue (como en la manta se entiende la Nación) dársele a la Nación María. Jura hoy a María por Universal Patrona de su Reino la Nación; y esto es dársele la Nación a María (...) Celebramos hoy Jurarla en esa su Sagrada Imagen nuestra General Patrona (aquí está mi asunto) y esto es dársele los Indianos a María, haciéndose ellos sus hijos» (p. 12).

Los mexicanos mediante esa Jura prometen fidelidad a la Virgen: «La Imagen de María arde en la América cuando se aparece en Guadalupe; y la América toda arde, y toda Jura, que ha de arder para siempre» (p. 18).

¿En qué se descubre el amor de María a los Indianos? En que es una Imagen Indiana y se asemeja a ellos, y además en que los hizo hijos adoptivos, no son sólo hijos naturales como los demás fieles. Por eso «a más del general culto debido a la relación de hijos, como naturales, le tributan el particular Juramento, que hoy hacen, con que publican, que la eligen su Adoptiva Madre» (p. 29) y de este modo consiguen un Patrocinio especial de la Virgen. Recurre a la Sagrada Escritura en que se dice que aunque Dios es Dios de todos los hombres, se le nombra como Dios de Jacob porque éste se singularizó con Dios, pues esto mismo se puede aplicar a los Indianos con la Virgen: María es madre de todos pero también los Indianos se han singularizado con María haciéndole el Juramento como Patrona de la America. Al final dice:

«El autor del Sermón deseando promover el Culto de la Santa Imagen de Guadalupe da a luz la siguiente Oración:

18 ITA Y PARRA, Bartolomé Felipe de, El Círculo de amor formado por la América Septentrional, jurando a María Santísima en su imagen de Guadalupe. Impreso en México en 1747, R 605 LAF.

Actas del I Congreso de Historia de la Iglesia y el Mundo Hispánico

Hispania Sacra 53 (2001) 
Antifona: Sicut lilium inter spinas, sic amica mea inter filias Adae.

v. In Conceptione tua, Virgo immculata fuisti

R. Ora pro nobis Patrem, cuius Filium peperisti.

Oratio. Deus, qui ad Indorum fidem propagandam, Mexicano Populo Imaginem Gloriosissimae Matris tuae Coelitus depictam floribus demonstrasti: concede, ut qui tanti miraculi participes sumus in terris eius intercessione conformes fieri Imaginis Filii sui mereamur in Coelis. Qui vivis, et regnas, etc.

\subsubsection{Otros oradores nacionalistas}

También hay en estas mismas fechas otros sermones interesantes, en los que nos detendremos menos.

Juan de Villa, dominico, predicó un sermón en $1733^{19}$ centrado en la idea de que María de Guadalupe es la misionera de América.

La idea más interesante de este sermón es que: «Dios, así copió, así trasumptó la imagen de Guadalupe, del original de su mismo Corazón. Dios omnipotente cuando copia, y cuando retrata, no saca la Imagen por el original, sino por el original del original; no retrata imitando fuera de sí, sino sacando de aquel original, que tiene dentro de sí» (p. 9).Y lo demuestra del siguiente modo:

«Haced os cargo de que esta bellísima Copia, ni representa a la Señora como estuvo en el Mundo, ni como está ahora en el Cielo (...) No como estuvo en el mundo, porque teniendo debajo de sus plantas la Luna (...) parece allí, no como mortal, sino como quien ya ha triunfado, y metido «debajo de los pies a la misma mortalidad. Tampoco representa a la señora, como está ahora en el Cielo; porque en el Cielo no está en pie, sino sentada (...) En el Cielo no está con los ojos bajos, sino levantados y puestos en la misma Divinidad. En el Cielo no está con las manos puestas, porque no está como quien ruega, sino como quien manda (...) Pues si esta Imagen, ni representa a María como estuvo en el Mundo, ni como está ahora en el Cielo. qué medio queda sino solo que la represente como está en el Corazón de Dios?» (p. 14).

Y la misión de esta Imagen era evangelizar el Nuevo Mundo y para demostrarlo se pregunta porque no adoraron en el pesebre al Niño cuatro Reyes en lugar de tres si eso era profecía de que todas las partes del Mundo conocerían a Dios, faltaba un rey que representara a América, y concluye «Notad lo que dice el Evangelista: Invenerunt puerum cum María Mater eius: hallaron los Magos al Niño con María: pues por eso no fue entonces la cuarta parte del Mundo; porque eso no con María, sino por María, había de hallar a Jesús: no

19 Villa SANCHEZ, Juan de, Sermón de la milagrosa Imagen de N.S. de Guadalupe de México, en la Festividad, que le celebran sus Devotos, el día del Proto-Mártir San Esteban, en la Iglesia del hospital del Amor de Dios de la misma ciudad. Impreso en México en 1734, R 1344 LAF. 
había de ser la Señora el término del hallazgo, sino el medio (...) la Estrella de la América, había de ser como fue la gran Señora aparecida en la tierra» (p. 19).

Y hace mención a continuación de la Mujer del Apocalipsis (Apoc, 12, 1) y la compara con la de Guadalupe a la que se le dieron dos alas de Aguila porque

\begin{abstract}
«Parece que quiso tomar la divisa de la región, adonde era enviada; a la manera de los antiguos Conquistadores tomaban el nombre de las Provincias que subjugaban (...) así tú, Santísima Señora, para tomar el nombre de Mexicana, tomaste la divisa de la Aguila de su Imperio; o lo más cierto es, no que tomaste el blasón, sino que corregiste el agüero; que si la Aguila en el Tunal fue el auspicio de su dilatado Imperio, tú, Aguila generosa, aparecida en sus Cerros, fueses el felicísimo presagio de que sobre las ruinas del pagano México, se había de fundar el glorioso Imperio de Cristo. Llegó la Mujer del Apocalipsis al Desierto; llegó la Virgen vestida de Sol, y calzada de la Luna, a los Cerros Mexicanos, y depuso las alas, que se le habían dado, las depuso, por eso no se las vemos, como quien llegó al termino de su vuelo, para jamás apartarse» (p. 21).
\end{abstract}

Se plantea que a los Pastores se les envió un Angel, porque los judíos usaban la razón y se les envió una criatura racional; a los Reyes una estrella porque eran sin uso de razón y se les habló con señas, ya que ellos entendían porque eran astrólogos. A los Americanos les envió una pintura porque era el modo en que se entendían, y además fue el modo de que a través de la Virgen conocieran a Dios.

Otro predicador importante de la época José Mariano de Elizalde Ita y Parra en 1743 en la Catedral de México, predicó un sermón ${ }^{20}$, sobre la Asunción que le dio pie para defender la insignia nacional.

Hace un paralelismo entre la misión de evangelizar de los Apóstoles, mandada por Cristo y la evangelización de México. Entre los países evangelizados por los Apóstoles no se encuentra América; es María la que elige a América, y en concreto a México para conseguir una especial gloria para Dios. Se basa en esta elección que hace María por México para afirmar que no podrán entrar errores. María tiene alas de Aguila y no de Paloma. Las alas le sirven para subir al cielo y para bajar a la tierra a convertir a los indianos. María vuela para el desierto, y para que no se confunda México con las demás naciones americanas, María vuela con alas de Aguila porque ésta es la insignia, que distingue a México de todas las Naciones Americanas, en donde Dios asegura a María su estabilidad, y permanencia, porque este fue el lugar que ella escogió para habitar aparecida en Guadalupe.

20 Elizalde ITA y PARRA, José Mariano de, Gloria de México en la mayor exaltación, y manifestación de la mayor gloria de María Santísima Señora Nuestra en su triunfante Asunción a los Cielos. Impreso en México en 1744, R 1138 LAF.

Actas del I Congreso de Historia de la Iglesia y el Mundo Hispánico

Hispania Sacra 53 (2001) 
María volaba para una Nación, que solo se entendía por caracteres, y se comunicaba por figuras: vuela pisando la Luna, porque si guiados de sus falsos ídolos los Totonaques, y Culhuas trajeron por señal para fundar esta ciudad, había que ejecutarlo donde se dejase ver en la laguna la Imagen de la Luna; que de ahí vino el nombre de México. Así debe aparecer María, encima de la Luna para que al verla los Mexicanos sobre esta figura que sirvió de señal para la situación de esta Ciudad, les sirva también de indicio de que tiene sujeta en esta Corte, la infidelidad y que tiene firmemente establecida la Fe católica: «para que de la mutabilidad que anuncia aquella no se tema: y de la firmeza, estabilidad, constancia, y perpetuidad, que simboliza el Sol, no se desconfíe.» (p. 29).

\section{LA IMAGEN DE LA VIRGEN DE GUADALUPE EN APOCALIPSIS 12}

«Apareción en el cielo una señal grande, una mujer envuelta en el sol, con la luna debajo de sus pies, y sobre la cabeza una corona de doce estrellas (...). Pero fuéronle dadas a la mujer dos alas de águila para que volase al desierto, a su lugar».

Rayando la primera mitad del siglo, en 1748, Francisco Javier Carranza, el 12 de diciembre en el Santuario de Guadalupe predicaba un sermón ${ }^{21}$ interesante por su carácter apocalíptico. En efecto, señalaba que los primeros evangelizados serán los últimos y los últimos (que son los Americanos) los primeros «La que hoy es Metrópoli de la fe, será en el fin del mundo la Metrópoli de la Gentilidad: (...) Luego la México, que fue la Metrópoli de la gentilidad, será la Metrópoli de la fe y de la fe por aquella amenísima Imagen, que recién convertida a la fe se declaró por su Madre» (p. 8). En consecuencia la Virgen de Guadalupe será la Protectora de la universal Iglesia en el fin de los tiempos, y su Santuario será el asilo de la Cátedra de San Pedro en la consumación de los siglos.

En su sermón apocalíptico no podía dejar de referirse a la imagen de la mujer del Apocalipsis 12 e identificar a la Virgen de Guadalupe con el Aguila que es el blasón de México y dice que el Dragón no perseguirá a la mujer más porque el Aguila (que es símbolo de la Iglesia e imagen de la Señora de Guadalupe) pondrá por medio un Océano y la Iglesia vendrá a ponerse bajo la protección de Guadalupe, atravesando a otras tierras. A continuación destaca que en el idioma mexicano Cerro de Tepeyac significa nariz de piedra y de ahí deduce que la Virgen olerá el mal olor del Anticristo y en Guadalupe será el sitio don-

21 CARRANZA, Francisco Javier, La Transmigración de la Iglesia a Guadalupe. Impreso en México en 1749, R 1230 LAF. 
de no se deje de celebrar la Eucaristía en la persecución del Anticristo, citando el oráculo de Daniel 11, 31 y 12, 11.

Afirma que si Guadalupe es la Patrona de toda América y lo será en el futuro de la Iglesia, «de aquí infiero que aquel Monarca universal de todo el mundo, que anuncian las Escrituras, y que explican los doctores, no ha de ser otro que el Católico Rey de las Españas (...) que aquella Señora, que aquella Imagen, que ha de proteger a toda la Iglesia le ha de conservar el Imperio a aquel Rey Católico a quien se lo conquistó» (p. 25).

Y como última «profecía» dice «no les manifestará Dios a los Americanos todas aquellas espantosas señales de sus tremendos juicios, ya que les hizo favor tan singular, como haberles dado la floridísima Imagen de su Madre» (p. 27).

Al siguiente año, en 1749, en San Luis Potosí, Antonio Flores predicaba un sermón ${ }^{22}$ centrado en que la Virgen de Guadalupe es una concepción celestial y un nacimiento indiano. Repite ideas anteriores: retoma la escena del Apocalipsis 12 y la compara con la de Guadalupe: semejanza de las alas de Aguila, que son el Blasón de México, escogió a México por Patria de su nacimiento; y también para su manto la capa de Juan Diego tejida de los hilos del maguey, que produce México; desterró los demonios; utiliza la Luna como escabel porque ésta es la etimología del nombre de México. Esta nación «es la envidia de los extranjeros, por las benignas influencias de su Cielo; por la abundancia de sus mantenimientos; por lo delicioso de sus aguas; por lo vistoso de sus jardines; por la riqueza de sus minerales (...) solamente el reyno de las Indias goza la libertad de las guerras y la inmunidad de los Demonios, por la Concepción Celestial y nacimiento Mexicano de esta Imagen (...) Y es, que quiso María de Guadalupe, hacer a México, mas que a otro lugar, la Patria de su nacimiento; y por eso le dio tanta felicidad» (p. 12).

Cualquier festividad era buena para exaltar el nacionalismo mexicano y la Virgen de Guadalupe. Un ejemplo es el sermón predicado por Mariano Antonio de la Vega el 29 de septiembre de $1752^{23}$ con motivo de la fiesta de San Miguel Arcángel. Se identifica éste con el ángel que tiene la Virgen a sus pies y a partir de ahí interpreta todos los demás elementos de la Imagen, partiendo de Apocalipsis 12: Laguna de México, las alas de Aguila, la Luna, los demonios los identifica con los ídolos que San Miguel y la Virgen de Guadalupe destierran de México.

22 FLORES VALDES, Antonio, La Celestial Concepción, y su nacimiento mexicano de la Imagen de Guadalupe. Impreso en México en 1750, R 1337 LAF.

23 VEGA, Mariano Antonio de la, La más verdadera copia del divino Hércules del cielo y sagrado Marte de la Iglesia el Glorioso Arcángel Señor San Miguel, a las sagradas plantas de María Nuestra Señora en su Milagrosa Aparecida Imagen de Guadalupe para protección y Amparo de este Nuevo Mexicano Mundo. Impreso en México en 1753, R 1198 LAF.

Actas del I Congreso de Historia de la Iglesia y el Mundo Hispánico Hispania Sacra 53 (2001) 


\section{CONFIRMACIÓN DEL PATRONATO POR BENEDICTO XIV (1754)}

Después de muchos años de intentar que la Santa Sede reconociera el hecho milagroso y excepcional de la Aparición de María de Guadalupe, se consiguió que el Papa firmara una Bula en que se confirmase el Patronato, con fecha 15 de mayo de $1754^{24}$. Benedicto XIV concedió todo lo que se le pidió: Misa y Oficio propio para la fiesta, y una serie de Indulgencias. Redactó de su propia mano la Oración para la misa y el Oficio en las cuales se hacía referencia al Templo que la misma Virgen pidió que se le edificara, al singular Patrocinio de María, a las rosas del cerro, a la clemencia del cielo para con los mexicanos, a la devoción de incontables multitudes que acuden a su Santuario, a las apariciones a Juan Diego, y las palabras tan significativas para los mexicanos y que fueron tan repetidas antes y, sobre todo después: Non fecit taliter omni nationi en los sermones, y que había introducido Francisco de Florencia en su Estrella del Norte.

El 12 de diciembre de 1755 se estrenó el nuevo Oficio con Misa Pontifical que celebró el Arzobispo de México Manuel José Rubio de Salinas. En esa circunstancia se predicó un sermón ${ }^{25}$ en que se destacaba cómo gracias a la Aparición de la Virgen, se habían convertido al cristianismo, en México, millones de gentes y al final acude a Ella para implorar por los Indios que aún mantienen sus idolatrías.

La concesión papal fue celebrada en México los días 9, 10 y 11 de noviembre de 1756, con una procesión solemnísima, altares en las calles y fuegos artificiales, además de la predicación de sermones. El del día 10 le correspondió a Juan José de Eguiara y Eguren y el del día 11 a Cayetano Antonio de Torres. El mes de diciembre de ese mismo año se celebró la festividad Guadalupe nueve días en el Santuario.

El primero de los sermones ${ }^{26}$ de una especial calidad literaria en que demuestra su dominio de la Sagrada Escritura. Gira entorno a la idea de María

24 Vid. VelaZqueZ, Primo Feliciano, La Aparición de Santa María de Guadalupe, o.c., pp. 274293.

25 SANTISIMA TRINIDAD, Andrés de la, La Venerada y glorificada en todas las naciones, por haberse aparecido en estos Reynos. Impreso en México en 1759, R 1337 LAF.

26 EGUIARA Y EGUREN, Juan José, María Santísima pintándose milagrosamente en su bellísima imagen de Guadalupe de México, saluda a la Nueva España, y se constituye su Patrona. Impreso en México en 1757, R 1247 LAF. Eguiara y Eguren nació en 1696 en la ciudad de México y falleció allí mismo en 1763. Hijo de españoles. Fue Bachiller en Artes, y doctor en Teología. En 1749 fue nombrado rector de la Universidad de México y promulgado obispo de Yucatán en 1751, pero rehusó la mitra. En 1724 fue examinador sinodal del arzobispado y diputado de la Hacienda Real de la Universidad; en 1737 calificador del Santo Oficio de la. Desde 1709 mantuvo una Academia en el Oratorio 
como portadora de paz y lo articula a partir de la Visitación de María a su prima santa Isabel y la visita de María de Guadalupe a México.

María saludó a Nueva España pintándose milagrosamente en la capa del mismo indio, y dejándole su efigie al Nuevo Mundo y lo hace así por acomodarse al estilo del país mexicano, pintando su figura y lo que les quiere transmitir en jeroglíficos. Al pintarse, saluda y al saludar se constituye como Patrona. El oficio de los patronos es defender a sus clientes, librarlos de los males y concederles los bienes, y esto es lo que ha hecho la Virgen desde hace dos siglos y veinticinco años. Los mexicanos han correspondido a esa predilección construyéndole tres templos, en el mismo sitio que eligió la Virgen, edificando en ciudades y pueblos, iglesias, capillas, altares, escribiendo libros, historias, sermones, poemas, le ha dedicado novenarios, romerías, súplicas, procesiones y fiestas solemnísimas, congregaciones, y eligiéndola como universal Patrona.

El orador del día $11^{27}$ destacó que la Confirmación Apostólica era la total firmeza del mismo Patrocinio y retomando el tan citado pasaje del Apocalipsis 12,1 comenta que «decir que aquella gran Mujer Apocalíptica fuese expresiva representación de nuestra Aparecida en Guadalupe, era antes concepto; hoy ya parece, que es verdad sólida»(p. 15). Lo que viene a demostrar lo que tantas veces han defendido los predicadores: que la Imagen de Guadalupe es «una Copia la más viva del Original de S. Juan» (p. 16).

Atribuye a la Virgen de Guadalupe el que se allanasen las dificultades de la Confirmación porque se carecían de noticias originales, ni papeles auténticos del Milagro, y Aparición «que o por desgracia del tiempo no se archivaron, o por suma fatalidad se perdieron, o por alguna incuria no aparecen, hasta que disponga otra cosa la divina providencia por el Patrocinio de la Señora». Y a continuación relata la historia de los pasos que tuvieron que seguirse hasta alcanzar a aprobación papal. Cuenta que le llevaron al Papa una copia de la Virgen y comenta «Las copias de Guadalupe son como las de la luz, que ni sacan, ni pueden sacar a luz, lo que ella es en sí misma. (...) El pincel más delicado acaso copiará el cuerpo; pero no la Alma de la Pintura. (...) Pero sea tan feliz el pincel de alguno, que pueda copiar al vivo todas estas perfecciones de la bellísima Imagen: ninguno ciertamente lo podrá hacer con aquel esplendor, con aquel brillo, con aquel no sé qué, de particular encanto, y hermosura, que

\footnotetext{
de san Felipe Neri, que se trasladó a la Universidad, en la cual dos días a la semana se defendían conclusiones de teología.

27 TORRES, Cayetano Antonio de, Sermón de la Santísima Virgen de Guadalupe, Impreso en México en 1757, R 1337 LAF. El predicador era Colegial Real por Oposición en el de S. Ildefonso, Teólogo de la Nunciatura de España, Diputado de Hacienda de la Real Universidad, Catedrático Propietario del mismo lugar de Elocuencias y de Vísperas de Teología, Cura interino del Sagrario la Catedral, Propietario de la Parroquia de S. Sebastián.
} 
sólo pudo darle el pincel de Dios « (pp. 32-33). Esta misma idea aparece repetida con cierta frecuencia en los sermones con el fin de demostrar el carácter milagroso de la Imagen.

Los actos en conmemoración de la Confirmación del Patronato se celebraron por toda Nueva España como lo demuestran los sermones encontrados ${ }^{28}$. Todos desarrollan, aproximadamente las mismas ideas: la intervención especial de la Virgen para conseguir esta aprobación para la cual no se podía presentar documentos escritos, aprobación debida en parte a la fe de los indianos y cómo se demuestra con este hecho la predilección de María por los mexicanos. Uno de ellos, el más posterior ${ }^{29}$, se plantea si es justo que México se quede con la Virgen de Guadalupe o la devuelva al Cielo, ya que dice que el Angel que sujeta a la Virgen es muestra de que vino del Cielo y que quiere llevarla al Cielo porque el Papa al confirmar el Patrocinio acredita ser originaria del Cielo. Muestra de su acendrado cariño a la Virgen de Guadalupe son estas palabras:

«Lo que si concedemos (y es mucha fortuna para el Cielo) es que allá le bordaron el vestido, allá la adornaron como a quien es; pero la Santa Imagen es natural y originaria de las Indias; de lo que hace gala su amor: pues se fabricó de una humilde capa y bronca tilma «(p. 10).

Y por tanto, si alguien quiere arrebatarla es «preciso que primero quitarais a los Americanos la vida, para que le llevarais el alma: eso no celestes Cortesanos, porque se hacía forzoso, que descerrajarais la custodia, que rompierais el relicario, para que os llevarais la reliquia: era forzoso digo, romper nuestros pechos, que en la ocasión son escudos de bronce, son muros de diamantes; para que nos arrancarais del pecho la pretendida joya. Tanto se nos metió por

28 PONCE DE LEON, José Antonio Eugenio, El Patronato, que se celebra, suplemento del testimonio, que no hay, de la aparición de la Santísima Virgen de Guadalupe Nuestra Señora. Impreso en México en 1757, R 1247 LAF; RodrigueZ VALLEJo Y DIEZ, José, Sermón con que la ciudad de Querétaro, y sus Sacratísimas Religiones celebraron la Confirmación, que del título de Principal, y Universal Patrona del Reyno de la América. Predicado el 8.X.1757. Impreso en México en 1758, R 1230 LAF; VALDERAS, Ignacio, Sermón de Nuestra Señora de Guadalupe de México, que en su ciudad de Querétaro [...] predicó en el día último del Solemnísimo Novenario, que se celebró por la Confirmación Pontificia de el Patronato Universal y Primario de la misma Señora en su Aparecida Imagen. Predicado el 16.X.1757. Impreso en México en 1758, R 1337 LAF; DIAZ DE ALCANTARA, José, Madre propia y natural de los septentrionales americanos la Santísima Virgen María Nuestra Señora aparecida en su Soberana milagrosísima Imagen de Guadalupe. Oración panegírica, que para solemnizar la Confirmación del Universal Patronato, de la Emperatriz de la Iglesia en este Nuevo Reyno predicó. Predicado el 18.X.1757 en la Catedral de Durango. Impreso en México en 1758 , R 1247 LAF.

29 REYNOSO, Sancho, La Injusticia por derecho justificada por gracia. Impreso en México 1759, R 1337 LAF. 
el corazón su hermosura! y por tanto, apelamos del tribunal, y juicio del derecho común, y ordinaria providencia al privativo tribunal, y gabinete de Dios, y de María, donde se derraman gracias, y privilegios para justificar nuestra posesión venturosa» (p. 13).

Los sermones posteriores, en concreto los de los años $1765^{30}, 1768^{31}$ y $1773^{32}$ predicados el 12 de diciembre en lo que era ya Colegiata de Guadalu$\mathrm{pe}^{33}$ y en la Iglesia de San Felipe el Real, destacan: los rasgos indianos de la Virgen que se viste con las mismas ropas que los naturales; la permanencia de la pintura; que México es un país afortunado y elegido por María.

Hay que señalar que parece que en el último tercio de siglo se había perdido esa vibración de años anteriores y se había caído en cierta devoción cansina a tenor de las palabras del citado sermón de 1773:

«¿Pero que distintas son las máximas del siglo? Hoy quieren pasar en el mundo por verdaderos hijos y devotos de María, los que acaso no tienen otra práctica de religión que alistarse en sus congregaciones, ocuparse en un círculo de oraciones y ejercicios exteriores, adornar sus altares y concurrir a la solemnidad de sus festividades. Yo alabo y venero estas costumbres religiosas, que ha canonizado la piedad de los fieles y la práctica de la Iglesia; pero si confiados en ese culto exterior y superficial, no se reforma el corazón, será vana vuestra confianza, y no seréis verdaderos hijos de María. Este género de devoción suele ser un ingenioso artificio del amor propio para acallar los gritos de una conciencia delincuente, y para gozar en medio de una vida criminal, de una paz falsa (...) Para conseguir estos dos efectos tan contrarios y repugnantes, se figuran en María una madre tan indulgente y amorosa, que con el tibio obsequio de unos cultos exteriores y superficiales, les tendrá, aun en medio de sus más abominables escándalos, preparadas sus misericordias. Se persuaden que la libertad del pecador la mira María como un atributo esencial de su piedad, y vanamente confiados en que María es madre de misericordia y de gracia, no se avergüenzan de ser hijos de la iniquidad y de la culpa» (pp.16-17).

« $\mathrm{O}$ dichosísimos mexicanos! A vosotros os toca por muchos títulos desempeñar el glorioso renombre de hijos de María, y servir de modelo y ejemplar a los verdaderos devotos de esta gran madre. Vosotros sois la porción elegida, el pueblo de adquisición de su amor y su piedad: a vosotros os visitó y prometió su protección y su amparo, a vosotros os declaró por hijos suyos» (p. 19). ${ }^{34}$

30 RUIZ DE CASTAÑEDA, Juan José, Sermón panegírico en glorias de María Santísima, bajo el título de Guadalupe. Impreso en México s.a., R 1574 LAF.

31 RoDRIGUEZ, José Manuel, El País afortunado. Impreso en México en 1768, R 619 LAF.

32 VEga y SANTA BARBARA, José, Oración, que en la festividad de nuestra Señora de Guadalupe de México, que celebró su Real Congregación en la Iglesia de S. Felipe el Real de esta Corte. Impreso en México en 1786, R 1256 LAF.

33 Vid. nota 2 supra.

34 Años más tarde vuelve a parecer de otro modo la misma idea. Exhortando a la generosidad para sufragar los gastos del Templo de Guadalupe dice el predicador: « $\mathrm{O}$ México! ¡Que tu abundancia haya de guarnecer de piedras preciosas a una mujer disoluta; y para el debido adorno de tu más recomendable Imagen no haya sino escasez, sino excusas, sino exageraciones de extrema pobreza! ¡O 


\section{RECAPITULACIÓN}

Los textos anteriormente recogidos ponen de manifiesto, como decíamos al comienzo de este trabajo, que los eclesiásticos tuvieron una notable influencia en la formación de la conciencia nacional. Recapitulando todos los elementos que aparecen en los ejemplos expuestos podemos ver lo siguiente.

Aunque no ha sido posible encontrar datos biográficos de todos los predicadores, podemos afirmar que aquellos de los que tenemos datos, es decir, los más importantes, habían nacido en Nueva España ${ }^{35}$, y que, por tanto, se sabían herederos de una cultura propia, de carácter mestizo, constituída por elementos españoles e indígenas. Al predicar subrayaban que los habitantes de México tenían uno serie de elementos comunes, que los distinguían de otros pueblos, no sólo de los españoles sino también del resto de los pueblos americanos. No era todavía el momento de defender abiertamente la independencia de la Metrópoli, que quizá no pretendían los oradores; ni quizá era oportuno referirse a tal emancipación de España, puesto que los sermones eran presididos, en muchos casos, por las máximas autoridades del virreinato (Virrey, Audiencia, Tribunales, ...). Por otra parte, conviene recordar que los sermones que hemos utilizado no son manuscritos, sino impresos, es decir, pasados por la censura, para obtener la licencia de publicación. Es obvio que cualquier referencia clara a la independencia habría impedido que esos sermones se imprimieran ${ }^{36}$. Con todo, es comprensible que esa insistencia en lo que distinguía a los mexicanos de los demás pueblos americanos y de la Metrópoli, contribuyese a crear una cierta mentalidad de nación diferente y, por tanto, necesitada de autonomía e independencia política.

Pueblo desvanecido con los vapores de la vanidad, que han soplado hacia ti las Naciones extranjeras! ¿Que hayas de gastar crecidas sumas en el lujo, y en llevar una ostenta que quizá no sufren tus fuerzas, y para la debida decencia y aliño de este Santuario, sea preciso valerse de arbitrios, que deberían excusar tu franqueza, y que realmente no sufragan los costos de empresas, poco dignas aun de la generosidad con que México nos ha enriquecido con todo género de dones? ¿Qué? ¿Te das por satisfecho, con que el sudor y afanes de nuestros mayores hayan levantado estas paredes? ¿Te imaginas desempeñada tu obligación, solo porque conservas un Templo puramente material, y sin aquella magnificencia que exige, la que ocupa en el Cielo un elevadísimo trono de gloria y majestad? [compara con el Templo de Jerusalén] (...) ¿ y México descansará en la devoción de algunos hijos verdaderos de $\mathrm{M}$, que quizá cortando diversiones, quizá minorando gastos precisos, sacrifican a este digno objeto toda la parte que pueden de sus rentas?» (pp. 12-14). LARRAÑAGA, José Ignacio de, Obligación de los americanos como especialmente favorecidos de María Santísima. Predicado en la Colegiara de Guadalupe el 14 de diciembre de 1794. Impreso en México en 1796, R 1256 LAF.

35 Vid. notas 10,13 y 26 supra.

36 Sobre algunas nociones generales de la predicación en Nueva España vid. SARANYANA, Josep-Ignasi (dir.), Teología en América Latina. Desde los orígenes a la Guerra de Sucesión (14931715), I, Iberoamericana-Vervuert, Madrid-Frankfurt, 1999, pp. 485-488. 
Sin embargo, lo más importante, en nuestra opinión, es que, para señalar lo diferente, los eclesiásticos pusieron de relieve lo netamente indígena, o sea, lo propio de los mexicanos. Por una parte, usando en los sermones términos náhuas, en unos casos españolizados y en otros no: Tepeyac, meztli, totonaques, culhuas, ayate, tilma, etc. Por otra parte, esforzándose por destacar las similitudes iconográficas entre la Imagen de la Virgen de Guadalupe y la indumentaria y geografía mexica. En esos sermones se puede detectar, por consiguiente, una incipiente elaboración de terminología «mexicana», que con posterioridad contribuiría a configurar el habla mestiza de las nuevas repúblicas del Hemisferio norte, particularmente de México. Este fenómeno se puede documentar tanto en la capital novohispana, como en otras ciudades importantes de los valles centrales de México.

En efecto; la Guadalupana es propia de los indígenas, dicen, porque se vistió con su traje, el ayate, la tilma, que es lo más propio de los indios, lo único que tienen y que les sirve para todo. Además la tilma está confeccionada con el maguey que es la planta propia de México. El rostro de la Virgen es de color moreno y apagado, semejante a los indígenas. En consecuencia, la Imagen es natural y originaria de las Indias, algo propio de los indios, que les convierte en hijos especiales de la Virgen, diferentes a los demás cristianos.

Además del atuendo, la Imagen tiene una relación especial con México por su enclave geográfico. Los antiguos mexicas se instalaron en la laguna de Tenotitzlan porque, según los augurios, debían hacerlo donde encontraran la señal del águila sobre un tuno. Pues bien, los oradores encuentran paralelismos entre la Imagen de Guadalupe, la figura del Apocalipsis 12 y el lugar de la Aparición.

María toma el nombre de Mexicana, es el Pájaro nacional, el Augural Aguila del México cristiano, del mismo modo que la Peña, el Tuno y el Aguila fueron los presagios de la Fundación Gentil. María de Guadalupe tiene a sus pies una luna, y precisamente Meztli significa Luna y México en náhuatl.

Estos simbolismos configuran una nueva Nación que, partiendo de los rasgos de los indios o indianos, ha llegado a ser cristiana. De hecho, se podría decir que precisamente esos elementos han sido queridos y preparados por la misma Virgen de Guadalupe, porque este fue el lugar que ella escogió para habitar definitivamente, como también lo demuestra el que perviva íntegra en una tela burda que no ha sufrido alteraciones a pesar de los siglos.

La consecuencia a la que van a llegar los oradores parece lógica: si María escoge un Nacimiento Mexicano es que quiso hacer a México su Patria. Y la fuerza de esta nueva nación está precisamente en lo que le distingue de los demás, es decir, en sus elementos indígenas, en lo único que tiene: el ayate, la manta del Indiano, la cual se entiende como la Nación. Así es como vencerá: 
«iO, y como si tuviésemos tiempo, desafiara Yo en nombre de nuestras Indias, a las Naciones del mundo, para vencerlas a todas juntas, solo con ese pobre Ayate!» (p. 12). En definitiva, Guadalupe es «la honra de nuestro Americano Pueblo; pues lo has honrado con tu Milagrosa Aparición»y, por tanto, los mexicanos la nombran por Universal Patrona de su Reino la Nación

Este recorrido por la oratoria sagrada novohispana de los siglos XVII y XVIII permite esclarecer, un poco más, el hecho de que la independencia mexicana tuviera un carácter diferente al resto de las otras naciones americanas. En efecto, la emancipación se ha explicado, en parte, por el carácter de la sociedad mexicana, donde el elemento indígena era muy fuerte y más consciente de su identidad que en otras partes, y donde el mestizaje tenía una fuerza especial. Por último, y en relación estrecha con el contenido de nuestro trabajo, es necesario recordar que el «grito de Dolores» que capitaneó el cura Hidalgo, y al que siguieron miles de indígenas y mestizos, se hizo en nombre y con el estandarte de la Virgen de Guadalupe.

\section{SELECCION BIBLIOGRÁFICA}

BASAVE Benítez, Agustín, México mestizo. Análisis del nacionalismo mexicano en torno a la mestizofilia de Andrés Molina Enríquez, FCE, México1992.

BRADING, David A. (ed.), Siete sermones guadalupanos, CONDUMEX, México 1994.

CABRERA, Miguel, Maravilla Americana y conjunto de raras maravillas, JUS, México 1989, edición y prólogo de Ernesto de la Torre Villar.

DE LA MAZA, Francisco, El guadalupanismo mexicano, FCE, México 21981.

De LA TORRE VILlaR, Ernesto, Los Guadalupes y la Independencia, Porrúa, México 1985.

DE LA TORRE VILlar, Ernesto-Navarro de Anda, Ramiro, Testimonios guadalupanos, FCE, México 1982.

Feliciano VelázQuez, Primo, La Aparición de Santa María de Guadalupe, JUS, México 1931.

HEREDIA CORREA, Roberto, Albores de nuestra identidad nacional, UNAM, México 1991.

NÓGUEZ, Xavier, Documentos guadalupanos. Un estudio sobre las fuentes de información tempranas en torno a las mariofanías en el Tepeyac, El Colegio Mexiquense-FCE, México ${ }^{2} 1995$

Poole, Stafford, Our Lady of Guadalupe. The Origins and Sources of a Mexican National Symbol (1531-1797), The University of Arizona Press, Arizona 1995.

VILlORO, Luis, Los grandes momentos del indigenismo en México, El Colegio de México-El Colegio Nacional-FCE, México 31996

Actas del I Congreso de Historia de la Iglesia y el Mundo Hispánico

Hispania Sacra 53 (2001) 